\title{
Aborto espontâneo e toxoplasmose ocular em um casal infectado com Toxoplasma gondii
}

\author{
Spontaneous abortion and ocular toxoplasmosis in a couple infected \\ with Toxoplasma gondii
}

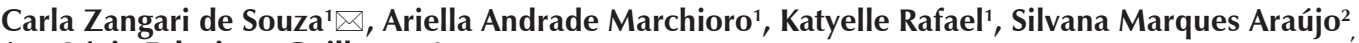 \\ Ana Lúcia Falavigna-Guilherme ${ }^{2}$ \\ 1 Programa de Pós-Graduação em Ciências da Saúde, Universidade Estadual de Maringá. Maringá, PR, Brasil. \\ ${ }^{2}$ Departamento de Ciências Básica da Saúde, Universidade Estadual de Maringá. Maringá, PR, Brasil.
}

Fontes de recursos: Coordenação de Aperfeiçoamento de Pessoal de Nível Superior (CAPES); Fundação de Amparo a Pesquisa do Estado do Paraná (Fundação Araucária)

\section{RESUMO}

Objetivos: Relatar os casos de um casal, em que a esposa apresentou toxoplasmose na gestação e o esposo, após 15 anos, foi diagnosticado com toxoplasmose ocular.

Relato dos casos: Gestante, grávida de gêmeos, residente de um estado na região Sul do Brasil. No primeiro mês de gestação apresentou sorologia não reagente para IgG e IgM anti-Toxoplasma gondii. Na sétima semana de gestação houve soroconversão (IgM e IgG anti-T.gondii reagentes) e aborto natural. $\mathrm{O}$ esposo, após 15 anos desde o episódio da esposa, queixou-se de visão embaçada/irritada. O exame de fundoscopia revelou lesões típicas de coriorretinite recidivante por toxoplasmose no olho direito. Os exames sorológicos foram IgG anti-T.gondii reagente e IgM anti-T.gondii não reagente.

Conclusões: Este relato, de um casal com desfechos clínicos importantes de toxoplasmose, em diferentes formas, enfatiza a relevância do problema da toxoplasmose, que nas suas diversas manifestações, pode trazer graves consequências para a vida de uma família.

DESCRITORES: Toxoplasma gondii; toxoplasmose congênita; toxoplasmose ocular; transmissão vertical; coriorretinite

\section{ABSTRACT}

Aims: To report the cases of wife and husband with toxoplasmosis. The woman acquired the infection during pregnancy while her husband was diagnosed with ocular toxoplasmosis 15 years later.

Cases report: A woman with twin pregnancy, living in southern Brazil, was seronegative for Toxoplasma gondii $\operatorname{IgG}$ and IgM antibodies in the first month of gestation. Seroconversion (positive T. gondii $\operatorname{IgM}$ and $\operatorname{IgG}$ antibodies) occurred in the seventh week of gestation, resulting in spontaneous abortion. Fifteen years later, her husband presented with eye irritation and blurred vision. The funduscopic examination revealed typical lesions of recurrent chorioretinitis in the right eye. The serological tests were positive for $T$. gondii IgG and negative for IgM.

Conclusions: This report of a couple with important clinical outcomes of two different types of toxoplasmosis underscores the importance of this disease which, in its various manifestations, may have serious consequences for a family's life.

KEY WORDS: Toxoplasma gondii; toxoplasmosis, congenital; toxoplasmosis, ocular; transmission, vertical; chorioretinitis. 
Abreviaturas: T. gondii, Toxoplasma gondii; Ig, imunoglobulina.

\section{INTRODUÇÃO}

A toxoplasmose é uma zoonose causada pelo parasita intracelular obrigatório Toxoplasma gondii, com aproximadamente um terço da população mundial contaminada. A infecção pode ocorrer pela ingestão de cistos teciduais presentes em carne crua ou mal cozida, ingestão acidental de oocistos eliminados em fezes de felídeos e dispersos em água ou solo, causando a contaminação de frutas e verduras, bem como transmissão vertical, por passagem de taquizoítas por via transplacentária, em gestantes com infecção aguda [1-5].

A taxa de transmissão materno-fetal e a gravidade das sequelas no feto estão relacionadas com a idade gestacional em que ocorreu a contaminação materna, imunidade da gestante, cepa do parasita e carga parasitária [6]. Os danos tissulares podem ser iniciados na gestação e completados após o nascimento, durante a infância ou mais tardiamente na idade adulta, provocando sequelas neurológicas e oculares [4]. A infecção pós-natal também é importante causa de doença ocular no Brasil, com envolvimento de genótipos atípicos $[7,8]$ e a causa mais comum de inflamação retiniana em pacientes imunocompetentes [9]. As lesões oculares recidivantes estão frequentemente associadas à perda da função visual [7-9].

O objetivo deste trabalho foi relatar a contaminação por T. gondii de um casal, em que a esposa teve toxoplasmose durante a gestação, que resultou em aborto espontâneo, e o esposo, 15 anos após, apresentou doença oftálmica. O relato foi aprovado pelo Comitê Permanente de Ética em Pesquisas Envolvendo Seres Humanos da Faculdade Ingá, Maringá, Paraná, em 31/05/2013, sob parecer $n$ o 301.312. Ambos os pacientes assinaram o Termo de Consentimento Livre e Esclarecido conforme aprovado pelo comitê.

\section{RELATO DOS CASOS}

\section{CASO 1}

Primigesta, 39 anos, com gravidez gemelar de sete semanas, residente na zona urbana de Maringá, Paraná, há quatro anos. Pesquisadora, docente universitária na área da saúde, possui hábito de preparar as refeições na própria residência, juntamente com o esposo, ambos procedentes de outro Estado do Brasil. A dieta do casal costuma ser com pouca ingestão de carnes, sendo estas bem cozidas, e rica em vegetais in natura, normalmente adquiridos na Feira do Produtor de Maringá. Essa feira conta com apoio técnico e da vigilância sanitária, e é diferenciada das demais feiras da região, pois os próprios produtores comercializam seus produtos. Em dezembro de 1997, com três semanas de gestação, apresentou sorologia não reagente para anticorpos Inunoglobulina (Ig) G e IgM anti-T.gondii (ELISA, MEIA e imunofluorescência indireta), bem como para rubéola, brucelose, listeriose e sífilis, e níveis normais dos hormônios folículo estimulante, tireoestimulante e prolactina. Na sétima semana de gestação, em janeiro de 1998, houve princípio de aborto, sendo administrada progesterona e inibina. Os exames sorológicos detectaram soroconversão para toxoplasmose, com IgM e IgG anti-T. gondii reagentes, pelas técnicas de imunofluorescência indireta, ELISA e MEIA. Foi administrada espiramicina, $250 \mathrm{mg}$ de 6 em 6 horas. Após sete dias, ocorreu o abortamento.

\section{CASO 2}

Empresário, 52 anos, esposo da paciente do caso 1. Após 15 anos do abortamento de sua esposa, em julho de 2012, apresentou queixas de visão embaçada e irritação no olho direito. O oftalmologista constatou miopia e elevada pressão intraocular, não sendo possível visualizar o fundo do olho. Após o tratamento do glaucoma houve redução geral da sensibilidade visual nos dois olhos. No mês seguinte, a retinografia não detectou alterações. Encaminhado a outro profissional, no mapeamento de retina foram observadas lesões de coriorretinite exsudativa, vitreíte e aumento da pressão intraocular no olho direito. A fundoscopia revelou lesões oculares cicatriciais e recidivantes no mesmo olho. Os exames sorológicos mostraram IgG anti- $T$. gondii reagente e IgM anti-T. gondii não reagente, por ELISA e MEIA. Em março de 2013 foi submetido a tratamento com sulfametoxazol/trimetoprim por 30 dias e prednisona por 21 dias. Após o tratamento houve regressão das manifestações clínicas. Atualmente, o paciente realiza acompanhamento semestral da coriorretinite.

\section{DISCUSSÃO}

Relatamos a ocorrência da toxoplasmose em um casal em que ambos apresentaram manifestações clínicas em períodos diferentes de tempo. Alguns estudos no Brasil observaram a severidade dos quadros clínicos por toxoplasmose, tanto congênitos quanto oculares, e chamam a atenção para a diversidade 
genética de cepas de $T$. gondii no país, com genótipos de média a alta virulência [6-9]. Pode-se aventar a possibilidade de que tenha ocorrido o aborto por estar a gestante no primeiro trimestre de gestação, no qual, embora a taxa de transmissão vertical seja pequena, quando ocorre infecção fetal há maior risco de gravidade [10].

Após uma década e meia de sua esposa ter tido o aborto de gêmeos, o esposo apresentou lesões recidivantes, devendo ser destacado que a toxoplasmose na região Sul do Brasil constitui importante causa de doença ocular, podendo ser desenvolvida dias, meses ou anos após a contaminação [7,8]. A toxoplasmose humana é adquirida por via oral, exceto a infecção congênita e raros casos de transplantes [1,2]. Os hábitos alimentares deste casal indicam probabilidade de que ambos tenham se contaminado com oocistos, o que concorda com a maioria das investigações sobre fatores de risco, tanto endêmicos quanto para surtos, no Brasil. Embora em alguns locais o consumo de carne mal cozida e embutidos artesanais possam representar importante risco de contaminação com cistos teciduais, no Brasil os principais fatores de risco são relacionados ao maior contato com solo e água contaminados por oocistos de $T$. gondii $[3,8]$. A preocupação com possíveis fontes de contaminação por $T$. gondii deve estar sempre presente no acompanhamento de gestantes. Entretanto, não se consegue identificar todas as gestantes que estão em risco de toxoplasmose congênita apenas pelos fatores de exposição, pois estes também podem estar presentes em muitas mulheres que não se contaminaram. Por outro lado, nem sempre se evidencia um fator de risco em uma gestante contaminada. Segundo Boyer et al. [11], a anamnese identificaria no máximo $48 \%$ das gestantes que adquiriram toxoplasmose. Por isso, é importante que seja feito o acompanhamento sorológico da gestante durante o cuidado pré-natal. Não obstante, é importante conhecer os fatores de risco, para poder orientar medidas de saneamento básico e instruir as pessoas mais vulneráveis (gestantes suscetíveis, pessoas imunodeprimidas) sobre prevenção primária $[4,5,11]$.

É muito importante que as pessoas sejam esclarecidas sobre todos os possíveis meios de contaminação pelo $T$. gondii além de carne mal cozida e contato com gatos, que são os mais conhecidos. Como aconteceu com a gestante do caso aqui relatado, o contato com solo em situações as mais diversas, incluindo consumo de legumes crus e frutas, e com fontes de água potencialmente contaminadas, são geralmente menosprezados. Os profissionais de saúde precisam ter conhecimento da ampla gama de exposições que as gestantes e pacientes imunodeprimidos devem evitar, e é essencial que as instruções sobre prevenção façam parte integrante dos cuidados no pré-natal $[1,2,4,5,11]$.

$\mathrm{Na}$ época em que ocorreu a toxoplasmose congênita no caso relatado, não se dispunha de estrutura técnica para execução da pesquisa molecular do parasito no estado do Paraná. Em 2012, foi realizada a pesquisa molecular (primer B1 e Toxo 4-5) do sangue periférico do esposo, mas, como também ocorreu em alguns estudos publicados $[12,13]$, por ser caso crônico de toxoplasmose ocular, não foi detectada a presença do DNA do parasito na circulação periférica, embora outros autores tenham demonstrado que isso é possível por ocasião de reativações oculares, mesmo quando a infecção já se encontra na fase crônica $[14,15]$.

Os casos aqui apresentados são muito comuns no Brasil, mas este relato se justifica por enfatizar a relevância do problema da toxoplasmose, que nas suas diversas e mais graves manifestações pode transformar e marcar para sempre a vida de uma família. Infelizmente a toxoplasmose não se inclui entre as doenças de notificação compulsória em nosso país, o que determina a carência de informações epidemiológicas mais completas, de forma a definir o real impacto desta devastadora doença na população brasileira.

\section{REFERÊNCIAS}

1. Dubey J. Toxoplasmosis of animals and humans. $2^{\underline{a}}$ ed. New York: CRC Press; 2010.

2. Tenter AM, Heckeroth AR, Weiss LM. Toxoplasma gondii: from animals to humans. Int J Parasitol. 2000 Nov;30(12-13):1217-58. http:// dx.doi.org/10.1016/S0020-7519(00)00124-7

3. Jones JL, Dubey JP. Waterborne toxoplasmosis-recent developments. Exp Parasitol. 2010 Jan;124(1):10-25. http://dx.doi.org/10.1016/ j.exppara.2009.03.013

4. Montoya JG, Remington JS. Management of toxoplasma gondii infection during pregnancy. Clin Infect Dis. 2008 Aug 15;47(4):554-66. http://dx.doi.org/10.1086/590149

5. Remington JS, Klein JO, Wilson CB, editors. Infectious diseases of the fetus and newborn infant. 7th ed. Philadelphia: Elsevier Saunders; 2011. 
6. Carneiro AC, Andrade GM, Costa JG, Pinheiro BV, Vasconcelos-Santos DV, Ferreira AM, Su C, Januário JN, Vitor RW. Genetic characterization of toxoplasma gondii revealed highly diverse genotypes for isolates from newborns with congenital toxoplasmosis in Southeastern Brazil. J Clin Microbiol. 2013 Mar;51(3):901-7. http://dx.doi.org/10.1128/JCM.02502-12

7. Grigg ME, Dubey JP, Nussenblatt RB. Ocular toxoplasmosis: lessons from Brazil. Am J Ophthalmol. 2015 Jun;159(6):999-1001. http://dx.doi.org/10.1016/j.ajo.2015.04.005

8. Silveira C, Muccioli C, Holland GN, Jones JL, Yu F, Paulo A, Belfort Jr R. Ocular involvement following an epidemics of Toxoplasma gondii infection in Santa Isabel do Ivaí, Brazil. Am J Ophthalmol. 2015 Jun;159(6):1013-1021.e3. http://dx.doi.org/10.1016/j.ajo.2015.02.017

9. Melamed J. Contributions to the history of ocular toxoplasmosis in Southern Brazil. Mem Inst Oswaldo Cruz. 2009 Mar;104(2):358-63. http://dx.doi.org/10.1590/S0074-02762009000200032

10. Kravetz J. Congenital toxoplasmosis. BMJ Clin Evid. 2010 Jun 28;2010.

11. Boyer KM, Holfels E, Roizen N, Swisher C, Mack D, Remington J, Withers S, Meier P, McLeod R; Toxoplasmosis Study Group. Risk factors for Toxoplasma gondii infection in mothers of infants with congenital toxoplasmosis: Implications for prenatal management and screening. Am J Obstet Gynecol. 2005 Feb;192(2):564-71. http://dx.doi.org/10.1016/j.ajog.2004.07.031

12. Robert-Gangneux F, Dardé ML. Epidemiology of and diagnostic strategies for toxoplasmosis. Clin Microbiol Rev. 2012 Apr;25(2): 264-96. http://dx.doi.org/10.1128/CMR.05013-11

13. Vaudaux JD, Muccioli C, James ER, Silveira C, Magargal SL, Jung C, Dubey JP, Jones JL, Doymaz MZ, Bruckner DA, Belfort R Jr, Holland GN, Grigg ME. Identification of an atypical strain of Toxoplasma gondii as the cause of a waterborne outbreak of toxoplasmosis in Santa Isabel do Ivai, Brazil. J Infect Dis. 2010 Oct 15;202(8):1226-33. http://dx.doi.org/10.1086/656397

14. Mattos CC, Meira CS, Ferreira AI, Frederico FB, Hiramoto RM, Jr GC, Mattos LC, Pereira-Chioccola VL. Contribution of laboratory methods in diagnosing clinically suspected ocular toxoplasmosis in Brazilian patients. Diagn Microbiol Infect Dis. 2011 Jul;70(3):362-6. http://dx.doi.org/10.1016/j.diagmicrobio.2011.02.002

15. Silveira C, Vallochi AL, Rodrigues da Silva U, Muccioli C, Holland GN, Nussenblatt RB, Belfort R, Rizzo LV. Toxoplasma gondii in the peripheral blood of patients with acute and chronic toxoplasmosis. Br J Ophthalmol. 2011 Mar;95(3):396-400. http://dx.doi.org/10.1136/ bjo.2008.148205 